\title{
The Choice of Portfolio Based on the Theory of Cooperative Games and the Zeuthen's and Harsany's Method
}

\author{
Anna Sroczyńska - Baron \\ University of Economics in Katowice, Department of Applied Mathematics, \\ UI. Pułaskiego 25, 40 - 276 Katowice \\ E-mail: kozak@caprisoft.com.pl
}

\begin{abstract}
The theory of games as a domain of mathematics is one of the methods proper for making decisions in the world of economics when we do not know how the other subjects are going to act. It seems to be a suitable tool for gambling on the stock exchange. During gambling on the stock exchange, the problem of the choice of proper portfolio appears; the player wants both great profit and low risk. It is reasonable to limit the choice only to portfolios which belong to the effective set. Then the decision of choice of a particular portfolio is individual and depends on the player and his aversion to the risk. In this article this problem is presented as the game that is, the inner conflict of the player. On the one hand he is expecting a great profit, yet on the other hand he is expecting a low risk. Which portfolio should be pointed out to give the satisfaction to the player? The solution of this problem presented in this work is based on the theory of games, which treats the search for a proper portfolio as a two-person game. A suitable game was formulated and described. The analysis of the game as a cooperative one was performed. There is also an example provided explaining the way of acting with data coming from the stock exchange in Warsaw.
\end{abstract}

Keywords: portfolio, cooperative games, player, expected rate of return, measure of risk for share, expected utility

JEL codes: $C 70, C 71, G 11$

\section{Introduction}

The theory of games as a domain of mathematics is one of the methods for proper decision making in the world of economics especially when we are not certain of how the other subjects are going to act (Vega-Redondo, 2003). It seems to be a suitable tool to gamble on the stock exchange, for example it is possible to use infinite games for strategy of shares purchase or sale (Sroczyńska - Baron, 2008). So it can also help us to construct a portfolio. One of the most important tasks of a market player is the proper choice of shares for portfolio. When the expected profit and the level of risks are known, the market player has to choose one portfolio which appears to be the best for him. He wants to find a portfolio with the expected profit as high as possible and concurrently the risk as low as possible. The problem lies in finding such a portfolio that gives satisfaction in respect to both profit and risk. One can come across this problem in previous works (Sroczyńska - Baron, 2009, 2013). The solution of this problem presented 
in this work is based on the theory of cooperative games, which treats the search for a proper portfolio as a two-person game. The standard deviation and the expected rate are taken as measures of the risk and profit. The analysis of the game as a cooperative one is also performed.

The main aim of this paper is to show how it is possible to use the theory of cooperative games for the construction of a portfolio. The method of acting of the market player based on the theory of games will be exemplified in this work. Data will come from the stock exchange in Warsaw and a portfolio that consists of shares from three different companies will be built. It will be shown that the method of the construction of portfolio is proper irrespective of measures taken for both profit and risk by the market player.

Nowadays, when the economic crisis affects more and more people - including market players - it is reasonable to use every possible tool to limit unnecessary risk and raise profit. So the method for optimal portfolio based on cooperative games seems to be worth considering and helpful for people who want to invest in the stock exchange.

\section{Methodology}

In this work, the Markowitz model is the base for later consideration. Standard deviation is taken as a measure of risk and expected rate of return is taken as a measure of profit by a market player. Cooperative games are used to solve the examined problem. A special game called "portfolio - game" is constructed and solved by one of the tools of cooperative games - Zeuthen's and Harsanyi's method.

\subsection{Markowitz Model - Some Remarks}

In the Markowitz model, the expected rate of return is taken for the measure of expected profit and standard deviation is taken for the measure of risk for shares (Markowitz, 1966). When the $n$ historical rates of return for shares are known, one can calculate the expected rate for share " $i$ " as

$$
E r_{i}=\frac{\sum_{k=1}^{n} r_{i k}}{n}
$$

where $r_{i k}$ - rate of return in period " $k$ " of share " $i$ ", $n$ - number of historical observation.

The standard deviation can be calculated according to the formula 


$$
s_{i}=\sqrt{\frac{\sum_{k=1}^{n}\left(r_{i k}-E r_{i}\right)^{2}}{n}}
$$

where $r_{i k}$ - rate of return in period " $k$ " of share " $i$ ", $n$ - number of historical observation, $E r_{i}$ - the expected rate for share " $i$ ".

When the expected rates and standard deviation for shares are known, one can calculate the expected rate for portfolio as

$$
E\left(r_{p}\right)=\sum_{i=1}^{m} x_{i} E r_{i}
$$

where $x_{i}$ - weight of share " $i$ " in portfolio, $m$ - number of shares in portfolio, $E r_{i}$ - the expected rate for share " $i$ ".

The standard deviation is described as a root extracted from the sum of the following products

$$
\operatorname{cov}\left(r_{i}, r_{j}\right) \cdot x_{i} \cdot x_{j}, \quad i, j=1, \ldots, m,
$$

where $\operatorname{cov}\left(r_{i}, r_{j}\right)$ means covariance, $x_{i}$ - weight of share " $i$ " in portfolio

$$
\operatorname{cov}\left(r_{i}, r_{j}\right)=\frac{\sum_{k=1}^{n}\left(r_{i k}-E r_{i}\right)\left(r_{j k}-E r_{j}\right)}{n}
$$

where $r_{i k}$ - rate of return in period " $k$ " of share " $i$ ", $n$ - number of historical observation, $E r_{i}$ - the expected rate for share " $i$ ".

When the expected rate of return and standard deviation for portfolios are known, the player is obliged to make a decision and choose one. The best portfolios satisfy the effective set of the Markowitz model, in which the effective portfolio has the highest possible expected rate of given risk and the lowest possible risk of given expected rate (Haugen, 1993). When it is suggested to choose a portfolio that does not belong to this set, it is always possible to propose a portfolio which is better in respect of the risk or profit. So, where the set of portfolios is limited to the effective set, the decision of the choice of one particular portfolio belongs to the player and depends on his aversion to risk. One of the common methods is to determine the curves of indifference and find the point of contact between them and the effective set. It gives us the portfolio of maximal expected utility marked as portfolio Z in Figure 1 (Jajuga, 1997). 
Figure 1 The choice of portfolio of maximal expected utility

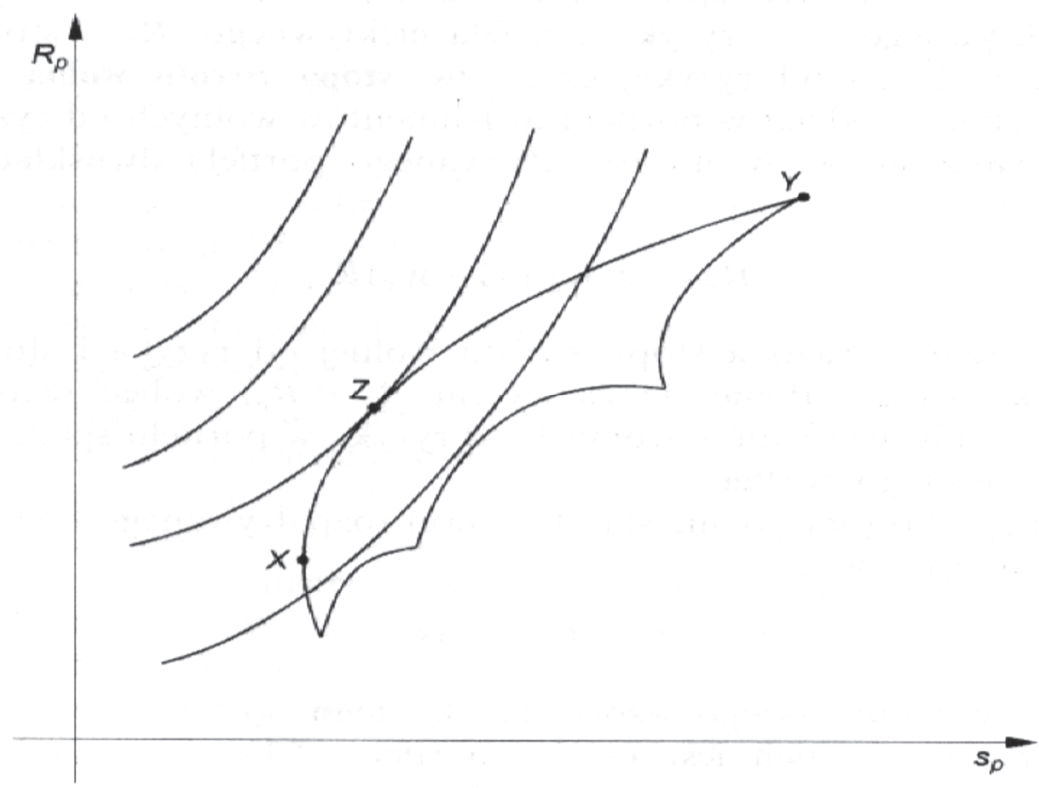

Source: Jajuga (1997)

Unfortunately, a big problem lies in constructing the curves of indifference for the player in reality, so the described method poses many troubles.

\subsection{Cooperative Games}

Two-person cooperative games are the model of game where players can communicate before the game and commonly choose one solution (Drabik, 2005). The traditional area of payment can enlarge by associative randomized strategies (it means every randomized strategy fixed by two players together). When the players cooperate they can reach every point of the created set. However, they limit this area to the set of jointly undominated outcomes, where point $(\alpha, \beta)$ is jointly dominated by $\left(\alpha_{1}, \beta_{1}\right)$ if $\alpha_{1} \geq \alpha$ and $\beta_{1} \geq \beta$. This set is called a joint maximum set. At this moment, the preferences of the two players become completely inverse and the players can no longer cooperate to gain common benefits. Neumann and Morgenstern noticed that it was hard to demand from players to agree and choose a strategy which gives them worse payment than this, which they could guarantee themselves. When we limit the joint maximum set in this way we are given the area of negotiation of the game. This is just a solution by Von Neumann and Morgenstern for the cooperative game. However, in some particular cases it is reasonable to assume that the players are ready to give up a part of their profits to get a solution satisfying the both of them. Therefore, it can be assumed that the solution has to belong to the joint maximum set and we should find an arbitrage solution there. One of the methods is the way of acting showed by Zeuthen and Harsanyi (Luce, Raiffa 1958). Player 
I pursues $\left(\alpha_{1}, \beta_{1}\right)$, and player II pursues $\left(\alpha_{2}, \beta_{2}\right)$. The relative losses of the players are the following:

$$
\frac{\alpha_{1}-\alpha_{2}}{\alpha_{1}}, \quad \frac{\beta_{2}-\beta_{1}}{\beta_{2}}
$$

The player, whose relative loss is smaller, gives in. The first player should resign if

$$
\frac{\alpha_{1}-\alpha_{2}}{\alpha_{1}} \leq \frac{\beta_{2}-\beta_{1}}{\beta_{2}}
$$

The second player should resign if

$$
\frac{\alpha_{1}-\alpha_{2}}{\alpha_{1}} \geq \frac{\beta_{2}-\beta_{1}}{\beta_{2}}
$$

The losing player can only offer the point without further concessions. The obtained solution is equal to Nash's solution of the market problem.

\subsection{The Game - Portfolio}

When we know the expected rates for shares and risk level connected with them, we can try to construct an optimal portfolio for the player. The player is obliged to make a decision. Knowing the particular value of the risk, he knows how big the expected winning can be. Yet, it can be stated, that the task of the market player is to find a portfolio with the highest possible profit at the lowest risk. It is commonly known that each player dreams about great profit yet, with the lowest possible risk not want to take a large risk. And so the question arises of how to point to a portfolio and ask which is the best?

Let us try to find a solution, based on the theory of games, in which we treat the search for a proper portfolio as a two-person game. The first player will be the part of our nature that is responsible for "caution and deliberation". The second player will be the part of our nature that is responsible for the so-called "lust for profit". The game payments of player I ("caution and deliberation") are different values of the risk for portfolio and the game payments of player II ("lust for profit") are different values of expected profit for portfolio. The first player desires a low risk, while the second one desires a big profit. This situation is not an antagonistic game because a good strategy for player I is not always a bad one for player II. It is possible to find a portfolio with a high risk and a low profit which none of the players finds it worth going for. Of course, it is very unnatural to treat the game of inner conflicts as a non-cooperative game so we will try to 
find the solution based on a cooperative game. Additionally, the order of negotiation is imposed. It is justifiable to assume that the players are ready to give up a part of their profits, to arrive at a solution satisfying the both of them, when it is the inner conflict of the market player. Therefore it can be assumed that the solution has to belong to the joint maximum set and we should find an arbitrage solution in this set.

\section{The Researches}

\subsection{Data}

The data used for researches comes from the Polish Stock Exchange in Warsaw. Let us take a standard deviation as a measure of a risk and an expected rate of return as a measure of profit. The task of the player is to construct a portfolio, which consist of three types of shares. The companies: KGHM Polish Copper SA, PKN ORLEN SA and KREDYT BANK SA were chosen - as three companies from index WIG 20 from different branches to ensure the risk diversification. One can use any method to choose companies for consideration, for example the synthetic measure of development in the stock selection (Węgrzyn, 2007, 2008). The necessary values for calculation are the following (based on data coming from the Stock Exchange in Warsaw from 31 ${ }^{\text {st }}$ January, 2010 till 30 ${ }^{\text {th }}$ June, 2011 as monthly rates).

Table 1 Market data KGHM Polish Copper SA, PKN ORLEN SA and KREDYT BANK SA (31/01/2010 - 30/06/2011)

\begin{tabular}{ccc}
\hline Company & Expected rate & Standard deviation \\
\hline \hline KGHM SA & 0.0468 & 0.0988 \\
\hline PKN ORLEN & 0.0277 & 0.0712 \\
\hline KREDYT BANK & 0.014 & 0.0424 \\
\hline
\end{tabular}

Source: Authors' own computation

\subsection{Run of the Researches}

First, the expected rates and standard deviations for different portfolios depending on the participation of three kinds of shares in the portfolio were calculated and the results in portfolios are presented in Fig. 2.

Of course, it is reasonable to limit this set only to portfolios which satisfy the efficient set of the Markowitz model (the periphery of the set from $A$ to $B$ in picture 1). This set consists of the best portfolios. When it is suggested to choose a portfolio which does not belong to this set, it is always possible to propose a portfolio which is better in respect of the risk or profit. For example, it is pointless to pursue the portfolio: $S_{p}=0.0489$ and $E\left(r_{p}\right)=0.026$ (it means $10 \%$ of KGHM, $65 \%$ of PKN Orlen and $25 \%$ of Kredit Bank shares) because of the 
possibility of portfolio: $S_{p}=0.0489$ and $E\left(r_{p}\right)=0.032$ (it means $42 \%$ of $\mathrm{KGHM}$, $31 \%$ of PKN Orlen and $27 \%$ of Kredit Bank shares). At this moment, the decision of the choice of one particular portfolio belongs to the player and depends on his aversion to risk. One of the common methods recalled earlier is to determine the curves of indifference and find the point of contact between them and the effective set. Because of a big problem to determine them for a real player, we will try to find the solution of the problem of how to find the best portfolio for the market player who desires on the one hand big profit, but on the other hand small risk with the use of the theory of games.

Figure 2 The set of portfolios of KGHM Polish Copper SA, PKN ORLEN SA and KREDYT BANK SA 30 ${ }^{\text {th }}$ June 2011

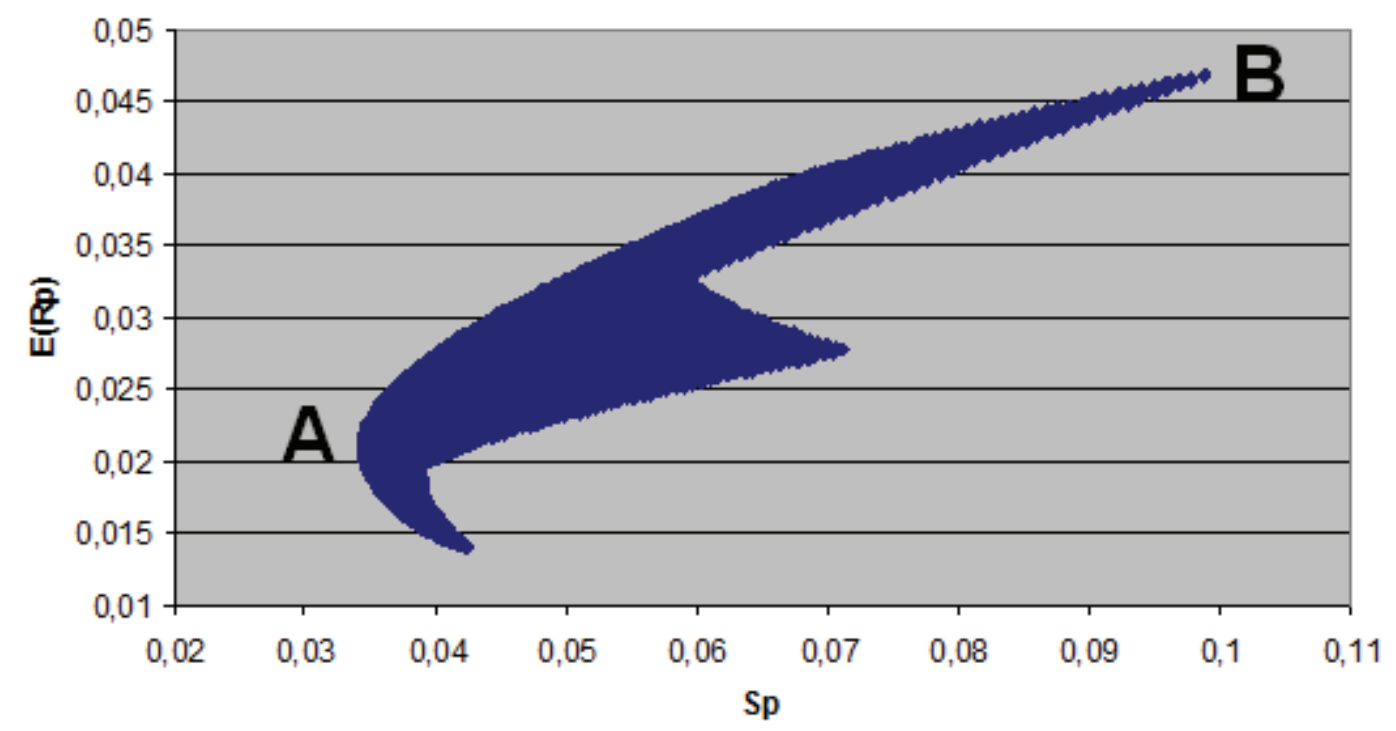

Source: Own computation

\subsection{Solution}

Let us look at Figure 2 as the set of all possible payments of one game. Of course, one transformation should be done to obtain the normal form of a game (till now, the first player desires as low a payment as possible - standard deviation). In Figure 3, it shows the set of all possible payments of the portfolio game after the transformation. Now, both players desire a payment which is as high as possible. The first player desires a high transformed risk, while the second one desires a big profit.

The opportunity set is shown in Figure3. When the players cooperate they can reach every point of the presented set. However, they limit this area to the set of jointly undominated outcomes and obtained a joint maximum set. It is showed in figure 3 as a periphery of the set from C to D. 
Figure 3 The set of all possible payments of the portfolio-game (KGHM Polish Copper SA, PKN ORLEN SA and KREDYT BANK SA 30 ${ }^{\text {th }}$ June 2011)

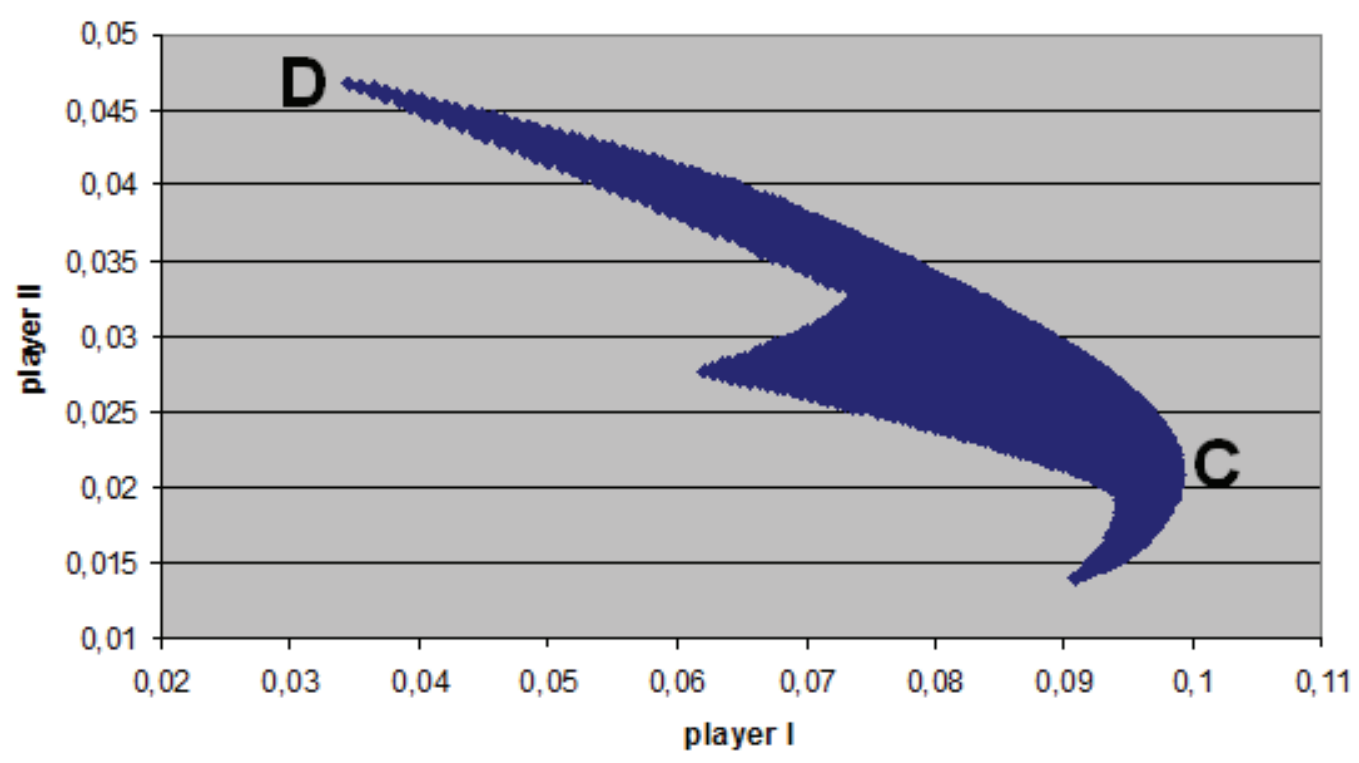

Source: Authors' own computation

The portfolios from the set of jointly undominated outcomes satisfy the effective set of the Markowitz model. One can say that a joint maximum set in the terminology of the theory of games is just the effective set in the terminology of the Markowitz model. Both of them consist of the same portfolios. At this moment, the preferences of the two players become completely inverse and the players can no longer cooperate to gain common benefits. Player I pursues the solution $(0.0987 ; 0.0217)$ whereas player II pursues the solution $(0.0345$; 0.0468). Let us use the Zeuthen's and Harsany's method to find the solution of this problem. So, player I proposes the point $(0.0987 ; 0.0217)$ and player II proposes the point $(0.0345 ; 0.0468)$. The relative loss of player I according to formula 6 is the following

$$
\frac{0.0987-0.0345}{0.0987}=0.65
$$

The relative loss of player II according to formula 6 is the following

$$
\frac{0.0468-0.0217}{0.0468}=0.54
$$

The relative loss of player II is smaller so he must give in. He should resign but he can offer the point without further concessions, for example $(0.07 ; 0.0379)$. Now, the relative loss of player I is 


$$
\frac{0.0987-0.07}{0.0987}=0.29
$$

The relative loss of player II is

$$
\frac{0.0379-0.0217}{0.0379}=0.43
$$

The relative loss of player I is smaller so he must give in. Continuing in this way, after calculations with the use of computer program, the players will gain the point $(0.08 ; 0.034)$ in the end. Then both players will have to agree. It is the solution of the portfolio-game by Zeuthen's and Harsany's method. Thus, the real solution is the point (before the transformation): $S_{p}=0.0532$ and $E\left(r_{p}\right)=0.034$. It means that the portfolio should consist of $45 \%$ of $\mathrm{KGHM}$ shares, $38 \%$ of PKN Orlen and $17 \%$ of Kredit Bank shares (Fig. 4). It could be called - universal portfolio of maximum utility.

Figure 4 Optimal portfolio in the sense of cooperative games of KGHM, PKN Orlen and Kredit Bank 30 th June 2011

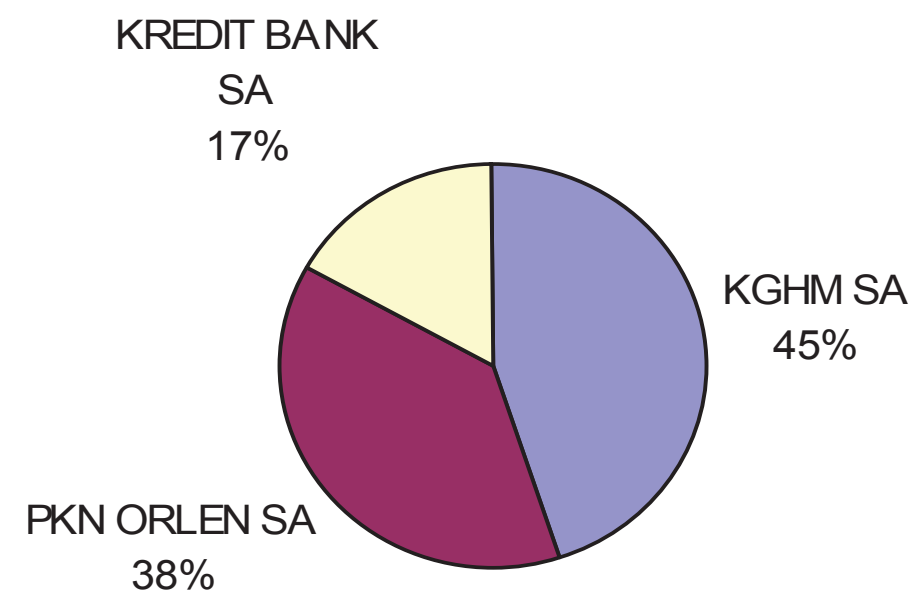

Source: Authors' own computation

Of course, it is possible to use any other method of cooperative games, for example Raiffa's method or the boundary average of payments.

\section{Conclusions}

When the market player knows a sufficient description of the strategies (possible risk and profit), he is able to gamble with the aid of the theory of games. The method of the choice of portfolio of shares based on the theory of games is presented and exemplified in this work. The Markowitz model was determined as one game (the inner conflict of the player) solved with the tools of the theory of games. The measures of expected profit and the level of risk used in this work 
are expected rate and standard deviation. However, it is visible that one can act in the same way when other measures of profit and risk will be taken. The method works irrespective of the measures taken for both profit and risk by the market player. What is more, it works irrespective of the number of companies taken for consideration. The market player acts in the same way when he wants to construct a portfolio which consists of two, three or as many as he wants companies. Calculations would not become harder at any case.

The presented method could help market players to make a decision and find a portfolio which gives satisfaction in respect to both profit and risk. Every tool helpful for market players seems to be important nowadays, when one must exist during the crisis all over the world.

Of course, it seems to be impossible to describe the stock exchange as one big game because of too many relations and connected with them are questions, problems, and doubts. However, it is with dead certainty that one can use some tools of the theory of games to solve partial tasks of the market player. An example of how to do it was presented in this work.

\section{References}

Drabik, E. (2005). Zastosowanie Teroii Gier w Ekonomii i Zarządzaniu. Wydawnictwo SGGW.

Haugen, R. (1993). Modern Investment Theory. Prentice Hall Inc.

Jajuga, K. and Jajuga, T. (1997). Inwestycje. Instrumenty Finansowe; Ryzyko Finansowe, Inżynieria Finansowa. Warszawa: PWN.

Luce, R. and Raiffa, H. (1958). Games and Decisions. Introduction and Critical Survey. New York: John Wiley\&Sons Inc.

Markowitz, H. (1966). Portfolio Selection. Journal of Finance, 7(1), pp. 77-91.

Sroczyńska - Baron, A. (2009). The Application of the Theory of Games for Purpose of Making a Choice of Portfolio. FindEcon Monograph Series: Advences in Financial Market Analysis, no 7, pp. 173-183.

Sroczyńska - Baron, A. (2008). The Application of Model of Shares Purchase Based on the Theory of Games in Investing on Market. Studia i prace Wydziału Nauk Ekonomicznych i Zarządzania Uniwersytetu Szczecińskiego, in Tarczyński W. ed., no 10, pp. 650-662.

Sroczyńska - Baron, A. (2013). The Choice of Portfoliio Based on the Theory of Games. Zeszyty Naukowe WSB we Wrocławiu. In Forlicz S. ed., no 2(34), pp. 379-392.

Węgrzyn, T. (2007). TMAI - Wpływ Grupowania Wskaźników Fnansowych na Uzyskiwane Stopy Zwrotu z Budowanego Portfela Papierów Wartościowych. In 
Adamkiewicz-Drwiłło, H. ed. Uwarunkowania Rozwoju Przedsiębiorczości. Determinanty i Narzędzia Zprzewagi Konkurencyjnej, PWN, Warszawa, p. 394.

Węgrzyn, T. (2008). TMAI - Wartości Nominalne Wskaźników Finansowych czy Tempo ich Przyrostu? Na Przykładzie Banków Notowanych na GPW w Warszawie. In Chrzan, P. ed. Modelowanie Matematyczne i Ekonometryczne na Polskim Rynku Finansowym, Wyd. AE Katowice, Katowice, p. 43.

Vega-Redondo, F. (2003). Economics and the Theory of Games. Cambridge University Press. 